\title{
COMPARAÇÃO MICROESTRUTURAL DE DOIS AÇOS PARA UTILIZAÇÂO EM MOLDES DE FABRICAÇÃO DE COMPÓSITOS*
}

\author{
Dirceu da Silva Junior ${ }^{1}$ \\ André Itman Filho ${ }^{2}$ \\ Rosana Vilarim da Silva ${ }^{3}$ \\ Pedro Gabriel Bonella de Oliveira ${ }^{4}$
}

Resumo

Os compósitos poliméricos com fibras naturais são geralmente fabricados com a técnica de moldagem por compressão a frio ou a quente, na qual as fibras são as compactadas com resina em um molde. Em geral, a matriz deve ser feita de um aço resistente à fratura, à fadiga e dureza adequada, pois grandes esforços são utilizados na prensagem do material entre 100 a $300^{\circ} \mathrm{C}$. Neste contexto, o objetivo deste trabalho foi avaliar a influência da temperatura na dureza dos aços SAE 8620 e SAE 8640. Amostras foram submetidas ao tratamento térmico de têmpera a $900^{\circ} \mathrm{C}$ e revenimento na faixa de $150 \mathrm{a}$ $650^{\circ} \mathrm{C}$. Posteriormente foram lixadas e polidas conforme os métodos convencionais de preparação metalográfica. Na revelação da microestrutura utilizou-se o reagente Nital $2 \%$. Para avaliar a influência da temperatura foram feitas medidas de dureza Rockwel C e análises microestruturais das amostras. Os resultados mostraram que os materiais apresentam uma microestrutura típica de martensita revenida após têmpera e revenido. No entanto, a dureza é superior a $45 \mathrm{RC}$ somente para o aço SAE 8640 até revenimento de $350^{\circ} \mathrm{C}$. Conclui-se, portanto, que apenas o aço SAE 8640 é adequado para fabricação de moldes para moldagem a quente de compósitos poliméricos.

Palavras-chave: Aço SAE 8620; Aço SAE 8640; Curva de revenimento; Conformação de compósitos.

\section{MICROSTRUCTURAL COMPARISON OF TWO STEELS FOR USING IN COMPOSITES CASTING MOLDS}

\section{Abstract}

The natural fiber polymeric composites are usually manufactured by hot or cold compression casting technique, which the fibers are impregnated with a resin in a mold. In general, the matrix must be set up of a steel with fracture, fatigue and hardness adequate resistance, because huge mechanical stresses are used at material compression between 100 and $300^{\circ} \mathrm{C}$. Therefore this article has as objective evaluate the temperature influence in the SAE 8620 and SAE 8640 steels hardness. Samples were submitted to quenching at $900^{\circ} \mathrm{C}$ and tempering in the range of 150 to $650^{\circ} \mathrm{C}$. Posteriorly it were sanded and polished according metallographic preparation standard methods. In the microstructure revelation Nital $2 \%$ reagent was used. To evaluate the temperature influence Rockwel $\mathrm{C}$ hardness measures and microstructural analysis were done with the samples. The results have shown that the materials exhibit an typical tempered martensite microstructure after quenching and tempering. However, hardness is greater than $45 \mathrm{RC}$ up to $350^{\circ} \mathrm{C}$ only for SAE 8640 . It's concluded, consequently, that only the SAE 8640 steel is suitable for hot casting of polymeric composites.

Keywords: SAE 8620 steel; SAE 8640 steel; Tempering curve; Composites casting.

1 Graduando em Engenharia Metalúrgica, Instituto Federal de Educação, Ciência e Tecnologia do Espírito Santo - IFES, Vitória, Espírito Santo, Brasil.

2 Professor do Programa de Pós-Graduação em Engenharia Metalúrgica e de Materiais - PROPEMM, Instituto Federal de Educação, Ciência e Tecnologia do Espírito Santo - IFES, Vitória, Espírito Santo, Brasil.

3 Professora do Programa de Pós-Graduação em Engenharia Metalúrgica e de Materiais - PROPEMM, Instituto Federal de Educação, Ciência e Tecnologia do Espírito Santo - IFES, Vitória, Espírito Santo, Brasil.

4 Aluno do Programa de Pós-Graduação em Engenharia Metalúrgica e de Materiais - PROPEMM, Instituto Federal de Educação, Ciência e Tecnologia do Espírito Santo - IFES, Vitória, Espírito Santo, Brasil. 


\section{INTRODUÇÃO}

Os compósitos com fibras naturais são geralmente fabricados utilizando a técnica de moldagem por compressão, onde as fibras são impregnadas com a matriz e o material é colocado na cavidade de um molde. Posteriormente a mistura das fibras com a resina será compactado com alta pressão a frio ou a quente.

Esta técnica garante compósitos com boa qualidade superficial e permite o uso de reforços com diferentes geometrias. Este método é principalmente utilizado no processamento de polímeros termorrígidos, como as resinas fenólicas, melamínicas, epoxídicas e as borrachas [1,2].

No caso da moldagem por compressão a quente, grandes esforços são utilizados na prensagem do material na cavidade, associados às temperaturas na faixa de $100 \mathrm{a}$ $300{ }^{\circ} \mathrm{C}$. Para suportar as condições severas da moldagem a matriz deve ser feita de um aço que atenda as solicitações mecânicas assim como tenha uma dureza adequada para atender aos esforços de atrito entre o molde e o material a ser moldado.

Dois aços indicados, quando se deseja uma combinação de resistência à fratura, à fadiga e dureza em temperaturas médias são o SAE 8620 e o SAE 8640.

O aço SAE 8620 é um aço baixo carbono ligado ao níquel, cromo e molibdênio, com composição química apresentada na Tabela 1, utilizado para cementação e posterior beneficiamento, pois apresenta pouca distorção após tratamentos térmicos. Este aço apresenta uma combinação de tenacidade, dureza, resistência à tração e ao impacto adequada para diferentes utilizações industriais.

O aço SAE 8620 é largamente usado devido ao baixo custo e alta qualidade. É aplicado geralmente em componentes mecânicos como pinos guia, anéis de engrenagem, colunas, cruzetas, catracas, coroas, virabrequins e eixos comando.

$O$ tratamento térmico de têmpera no aço SAE 8620 é realizado na faixa de 840 a $900^{\circ} \mathrm{C}$ e após cementação, o resfriamento pode ser feito em água ou em óleo com uma dureza entre 55 e $62 \mathrm{HRC}$ conforme as dimensões da peça [3].

O aço SAE 8640 é uma liga especial de aço médio carbono ligado ao cromo, níquel e molibdênio, com composição química apresentada na Tabela 1, desenvolvida durante a segunda guerra mundial. A adição de níquel substituindo o cromo é responsável pela alta tenacidade e resistência ao desgaste. Além disso, possui também alta resistência mecânica, boa usinabilidade e elevada temperabilidade.

Devido à alta tenacidade e resistência ao desgaste, o aço SAE 8640 é usado como aço ferramenta. Após tratamento térmico de têmpera na faixa de 850 a $900^{\circ} \mathrm{C}$, o SAE 8640 é utilizado na fabricação de eixos, bielas e virabrequins, na indústria agrícola, automobilística, de máquinas e equipamentos. O resfriamento pode ser feito em água ou em óleo e a dureza apresenta valores entre 58 a 64 HRC.

Tabela 1. Composições químicas comerciais dos aços AISI 8620 e AISI 8640

\begin{tabular}{ccccccc} 
Aço & $\mathbf{C}$ & $\mathbf{S i}$ & $\mathbf{M n}$ & $\mathbf{N i}$ & $\mathbf{C r}$ & $\mathbf{M o}$ \\
\hline SAE 8620 & $0,17-0,23$ & $0,10-0,40$ & $0,60-0,95$ & $0,35-0,75$ & $0,35-0,75$ & $0,15-0,25$ \\
SAE 8640 & $0,38-0,43$ & $0,15-0,35$ & $0,75-1,00$ & $0,40-0,70$ & $0,40-0,60$ & $0,15-0,25$
\end{tabular}

\subsection{Objetivo}

Determinar as curvas de revenimento dos aços AISI 8620 e AISI 8640 após tratamentos térmicos. 


\section{MATERIAIS E MÉTODOS}

As amostras foram preparadas conforme as seguintes etapas:

- Corte das barras dos aços AISI 8620 e AISI 8640.

Amostras com $12 \mathrm{~mm}$ de comprimento e $10 \mathrm{~mm}$ de diâmetro foram cortadas de barras dos aços comerciais SAE 8620 e SAE 8640.

- Tratamentos térmicos convencionais de têmpera e revenimento.

No tratamento de têmpera o forno foi estabilizado na temperatura de $900^{\circ} \mathrm{C}$ para colocação das amostras. Após 30 minutos as amostras foram retiradas e resfriadas em água. Posteriormente as amostras foram revenidas nas temperaturas de 150, $250,350,450,550$ e $650^{\circ} \mathrm{C}$ durante 40 minutos.

- Preparação metalográfica das amostras.

As amostras foram preparadas para análise metalográfica com lixas de número 80 , $180,220,320,400,500,600,1000$ e 1200. Posteriormente foram polidas com alumina de granulometria 0,3 e $1 \mu \mathrm{m}$. A microestrutura do material foi revelada com Nital $2 \%$.

- Análise microestrutural.

As observações das amostras tratadas termicamente foram realizadas em um microscópio óptico.

- Medição de microdureza

Para obter as durezas Rockwell $\mathrm{C}$ as amostras foram submetidas a uma pré-carga de $10 \mathrm{kgf}$ e posteriormente de $150 \mathrm{kgf}$ seguindo os procedimentos da norma NBR 6671.

\section{RESULTADOS E DISCUSSÃO}

A curva de revenimento dos aços na Figura 1 mostra a redução da dureza com o aumento da temperatura para o aço SAE 8640 enquanto que o aço SAE 8620 apresenta um pequeno aumento de dureza na faixa de 350 a $500^{\circ} \mathrm{C}$.

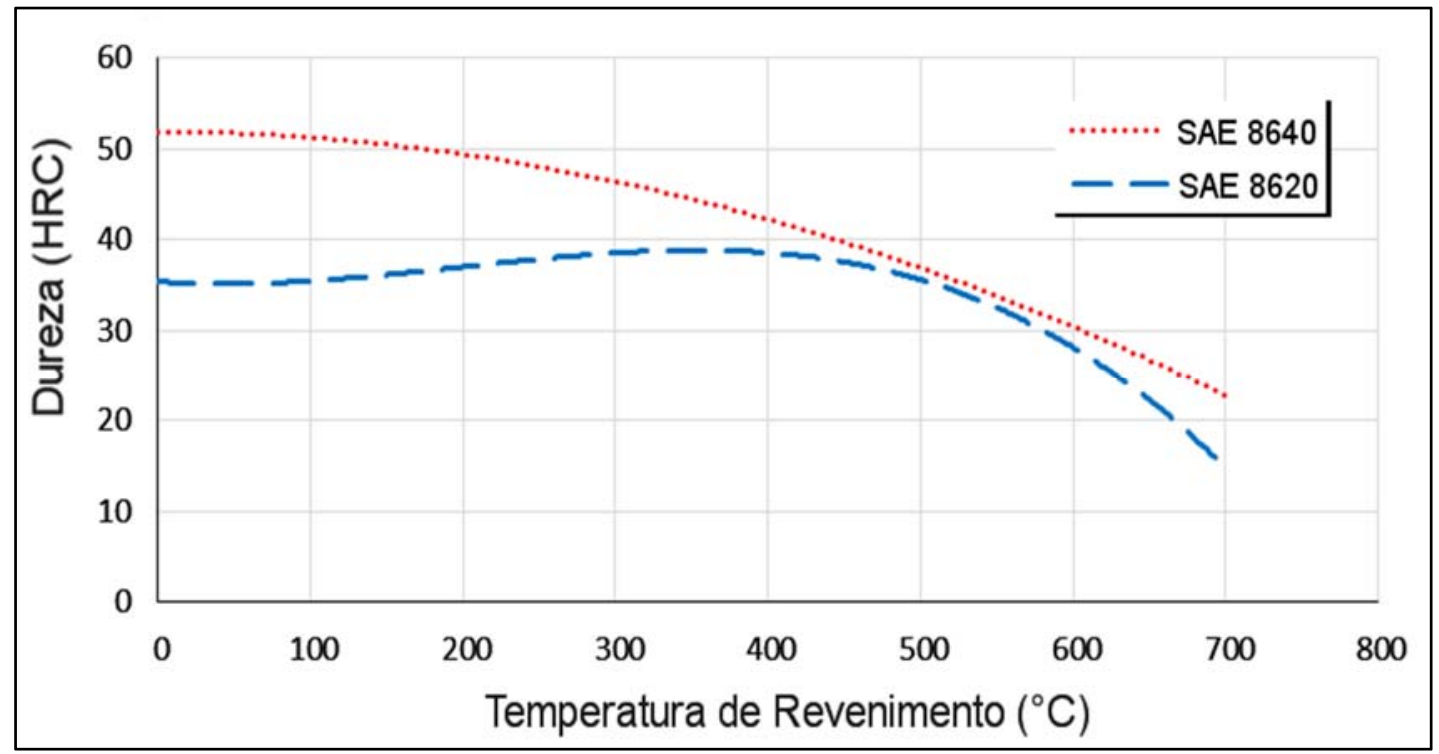

Figura 1. Curva de revenimento para os aços SAE 8620 e SAE 8640. 
Finas ripas de martensita formadas após o tratamento de têmpera são observadas nas Figuras 2a e 2b. O maior teor de carbono do aço SAE 8640 é responsável pelo aumento da espessura das ripas e da maior dureza do material

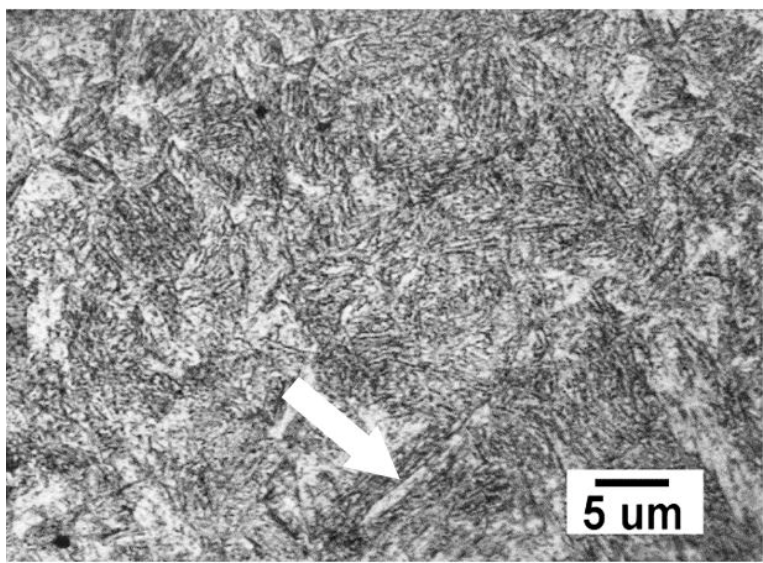

Figura 2a. Ripas martensíticas destacada pela seta. SAE 8620 temperado a $900^{\circ} \mathrm{C}$. Ataque Nital 2\%. Microscópio Confocal.

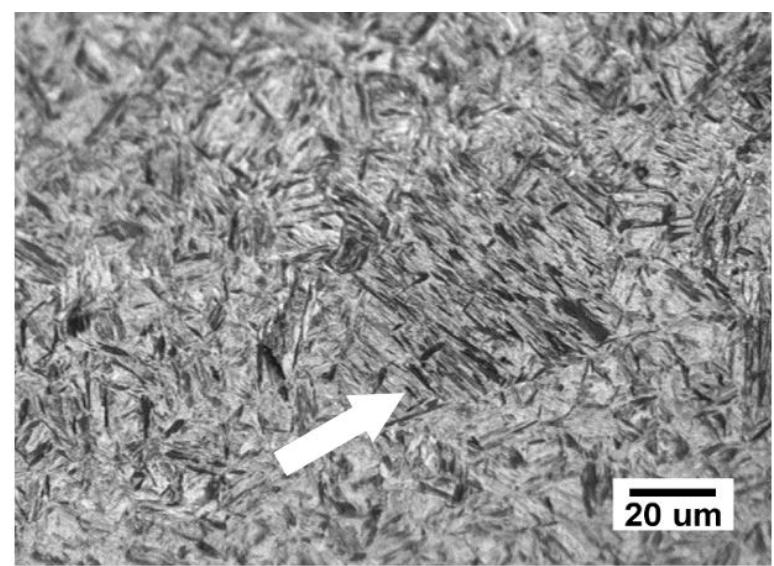

Figura 2b. Ripas martensíticas destacada pela seta. SAE 8640 temperado a $900^{\circ} \mathrm{C}$. Ataque Nital $2 \%$. Microscópio Confocal.

Para uma temperatura de $150^{\circ} \mathrm{C}$ o carbono se difunde e promove um alívio de tensões sem alterações na microestrutura do material que mantem o aspecto de ripas nas Figuras 3a e 3b. No aço SAE 8620 o carbono se difunde da martensita e se aglomera nas discordâncias, enquanto que no aço SAE 8640, pelo maior teor de carbono, ocorre a precipitação carboneto $\varepsilon$.

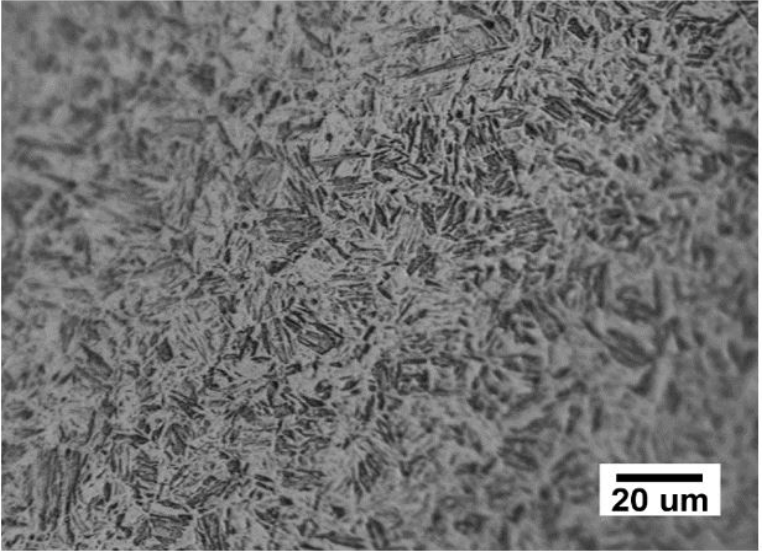

Figura 3a. Martensita revenida. SAE 8620 temperado a $900^{\circ} \mathrm{C}$ e revenido a $150^{\circ} \mathrm{C}$. Ataque Nital $2 \%$. Microscópio Confocal.

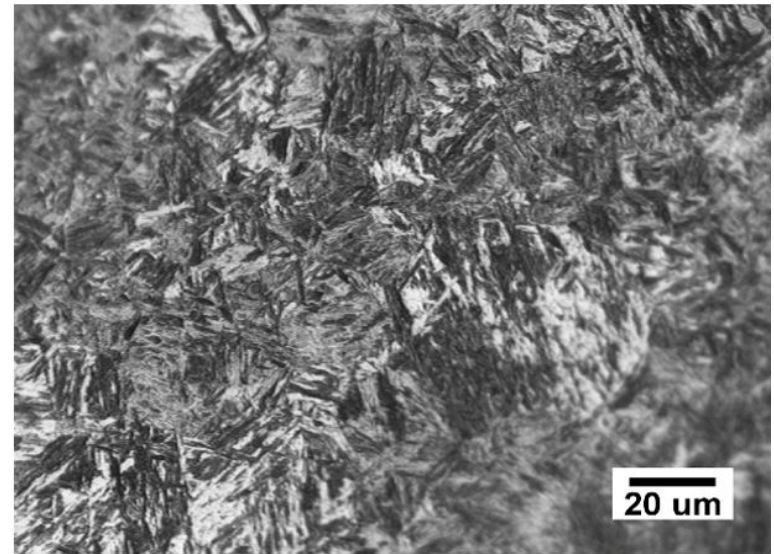

Figura 3b. Martensita revenida. SAE 8640 temperado a $900^{\circ} \mathrm{C}$ e revenido a $150^{\circ} \mathrm{C}$. Ataque Nital $2 \%$. Microscópio Confocal.

Com o aumento da temperatura a martensita perde a tetragonalidade e se transforma em uma martensita com baixo teor de carbono, promovendo a formação de uma estrutura de ferrita-bainita como visto nas Figuras 4a e 4b. É possível observar que no aço SAE 8640 há uma maior quantidade desta microestrutura quando comparado ao SAE 8620.

$\mathrm{Na}$ Figura 4b é notado o escurecimento da matriz do aço SAE 8640 devido a progressiva precipitação do carboneto $\varepsilon$ que facilita $o$ ataque, quando comparada com a Figura $3 b$. 
O aumento de dureza a partir de $350^{\circ} \mathrm{C}$ para o aço SAE 8620 como visto na Figura 1, ocorreu possivelmente pela transformação de austenita retida em martensita.

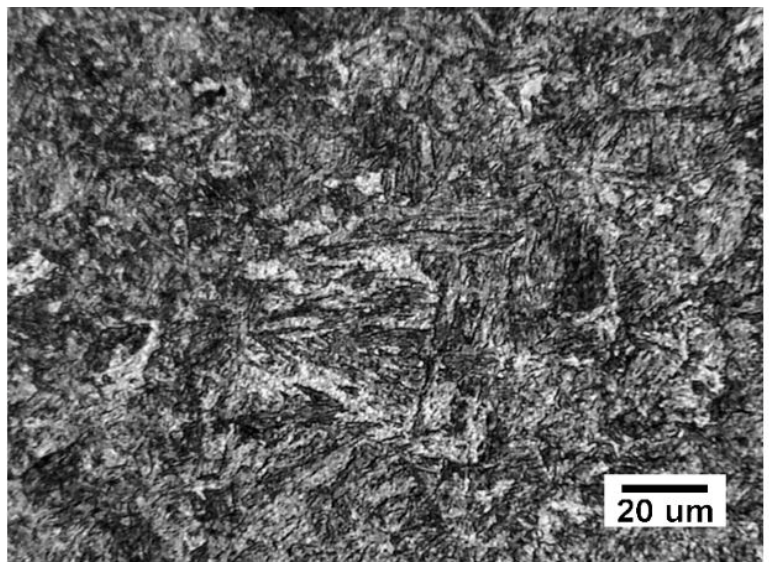

Figura 4a. Ferrita-bainita. SAE 8620 temperado a $900^{\circ} \mathrm{C}$ e revenido a $350^{\circ} \mathrm{C}$. Ataque Nital 2\%. Microscópio Óptico.

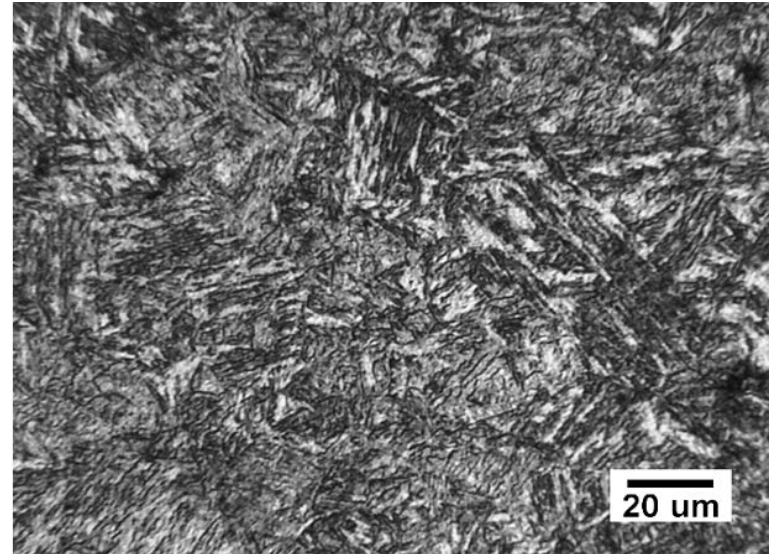

Figura 4b. Ferrita-bainita. SAE 8640 temperado a $900^{\circ} \mathrm{C}$ e revenido a $350^{\circ} \mathrm{C}$. Ataque Nital 2\%. Microscópio Óptico.

Com o progressivo aumento de temperatura a partir de $300^{\circ} \mathrm{C}$ as alterações das substruturas de discordância, através do mecanismo de recuperação, são evidenciadas pela contínua redução da dureza [4].

$\mathrm{Na}$ temperatura de $400^{\circ} \mathrm{C}$ o carboneto $\varepsilon$ se transforma em cementita e toda austenita retida, se presente, se decompõem. Assim a $450^{\circ} \mathrm{C}$ o aço SAE 8620 apresenta uma estrutura ferrita-bainita, com maiores grãos de ferrita. Na Figura 5a em contrapartida o aço SAE 8640 ainda mostra uma estrutura lamelar típica de ferrita-bainita na Figura 5b. Portanto a diminuição da dureza nesta temperatura é devido a maior formação de ferrita nos aços.

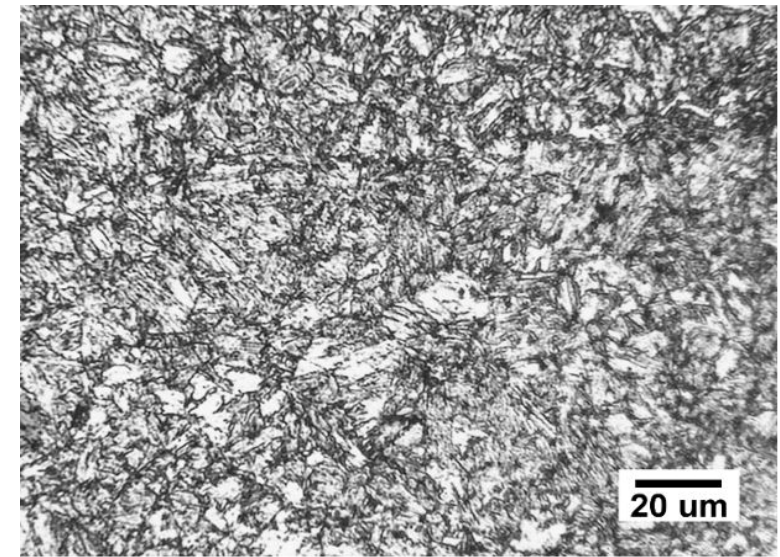

Figura 5a. Ferrita-bainita. SAE 8620 temperado a $900^{\circ} \mathrm{C}$ e revenido a $450^{\circ} \mathrm{C}$. Ataque Nital 2\%. Microscópio Óptico.

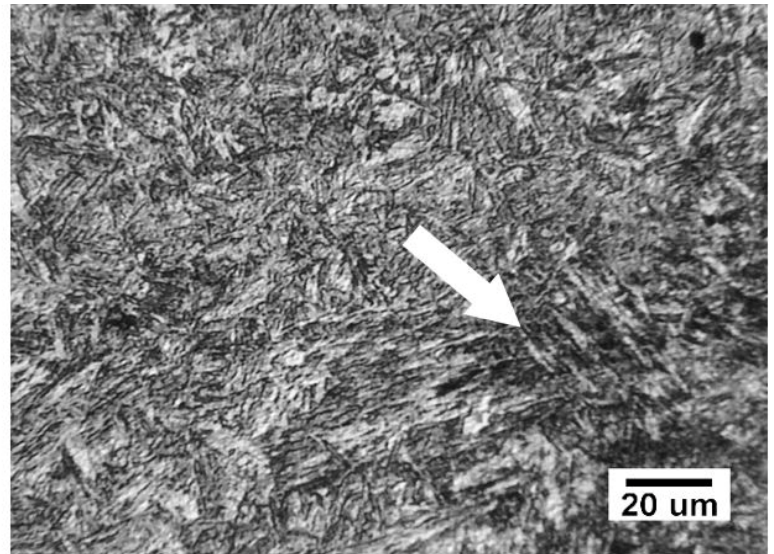

Figura 5b. Lamelas de ferrita-bainita destacadas pela seta. SAE 8640 temperado a $900^{\circ} \mathrm{C}$ e revenido a $450^{\circ} \mathrm{C}$. Ataque Nital 2\%. Microscópio Óptico.

Para o revenimento a $530^{\circ} \mathrm{C}$ é observada uma microestrutura de ferrita-cementita nas Figuras $6 a$ e $6 \mathrm{~b}$, como o aço SAE 8620 possui menor teor de carbono a ferrita se apresenta em grãos maiores. 


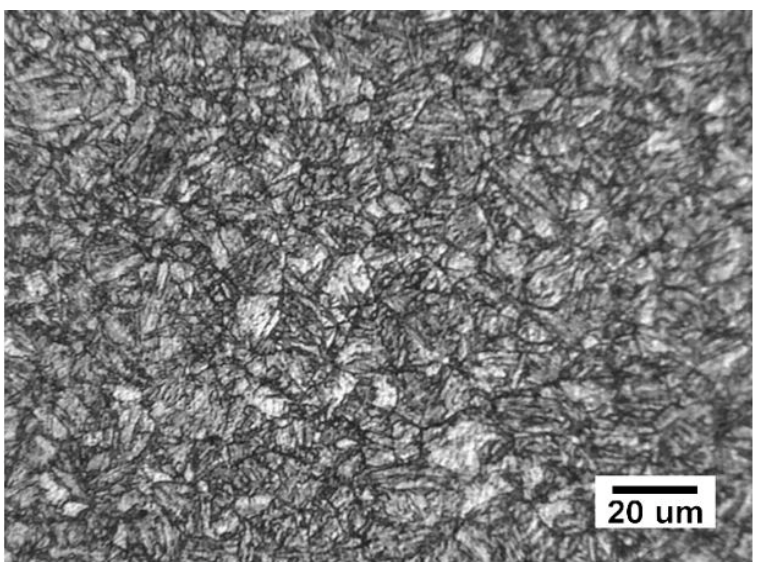

Figura 6a. Ferrita-cementita. SAE 8620 temperado a $900^{\circ} \mathrm{C}$ e revenido a $530^{\circ} \mathrm{C}$. Ataque Nital 2\%. Microscópio Óptico.

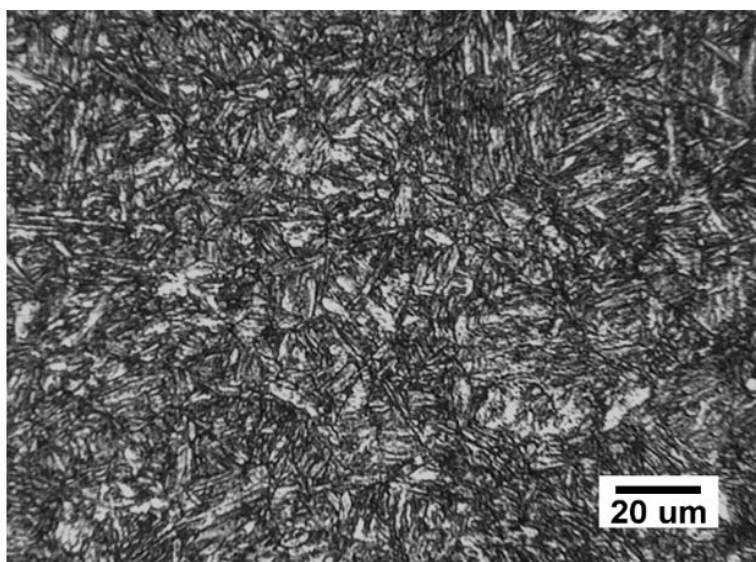

Figura 6b. Ferrita-cementita. SAE 8640 temperado a $900^{\circ} \mathrm{C}$ e revenido a $530^{\circ} \mathrm{C}$. Ataque Nital 2\%. Microscópio Óptico.

Nas Figuras 7a e $7 b$ observam-se pequenos glóbulos de cementita no interior dos grãos de ferrita. Há um aumento dos grãos de ferrita nesta temperatura e a diminuição da dureza dos aços [4,5].

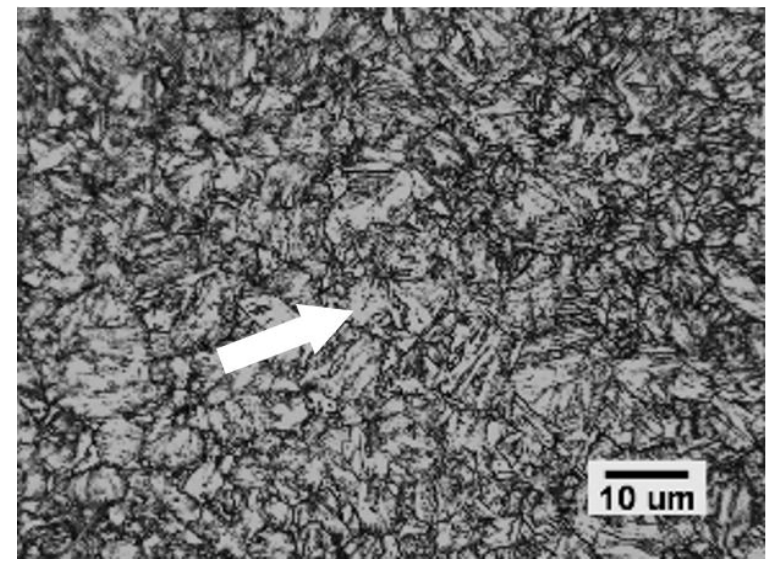

Figura 7a. Seta destaca possíveis precipitados de cementita globular. SAE 8620 temperado a $900^{\circ} \mathrm{C}$ e revenido a $600^{\circ} \mathrm{C}$. Ataque Nital $2 \%$. Microscópio Óptico.

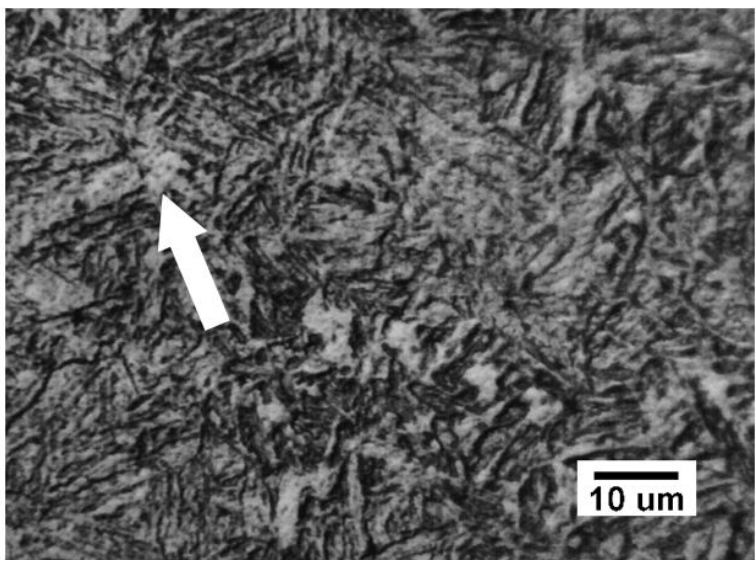

Figura 7b. Seta destaca possíveis precipitados de cementita globular. SAE 8640 temperado a $900^{\circ} \mathrm{C}$ e revenido a $600^{\circ} \mathrm{C}$. Ataque Nital $2 \%$. Microscópio Óptico.

\section{CONCLUSÃO}

Os aços SAE 8620 e SAE 8640 apresentam uma microestrutura típica de martensita revenida após os tratamentos térmicos realizados;

$\mathrm{O}$ aço SAE 8620 apresenta um aumento na dureza a $350^{\circ} \mathrm{C}$ causado possivelmente pela transformação de austenita retida martensita;

Para temperaturas de revenimento entre 500 e $600^{\circ} \mathrm{C}$ não há variação significativa na dureza dos aços;

Somente o aço SAE 8640 é adequado para fabricação de matrizes para moldagem a quente de compósitos poliméricos, pois apresenta dureza superior a $45 \mathrm{HRC}$ nas faixas usuais de conformação mecânica entre 100 e $300^{\circ} \mathrm{C}$. 


\section{Agradecimentos}

À Finep, a Fapes e ao CNPq pelo apoio financeiro e bolsa de iniciação científica.

\section{REFERÊNCIAS}

1 Nogueira CL, Marlet JMF, Rezende MC. Processo de Obtenção de Pré-impregnados Poliméricos Termoplásticos Via Moldagem por Compressão a Quente. Polímeros: Ciência e Tecnologia. 1999;Jul/Set:12-18.

2 Zhao AH, Chen JN. Preparation of single-poly tetra fluor ethylene composites by the processes of compression mold in gand free sintering. Composites part B: Engineering. 2011;42(5):1306-1310.

3 Silva ALVC, Mei PR. Aços e ligas especiais. $2^{\mathrm{a}}$ Ed. rev. e ampl. São Paulo: Edgard Blucher; 2006.

4 Tschiptschin AP, Goldenstein H, Sinátora A. Metalografia dos Aços. São Paulo: ABM. 1988.

5 Colpaert H, Silva ALVC. Metalografia dos produtos siderúrgicos comuns. $4^{\mathrm{a}}$ Ed. São Paulo: Edgard Blucher; 2008. 